Appliances are required to hold unstable joints but may never be used to attempt correction of a fixed deformity. When this exists, it is better to contour the appliance to the deformity than to endeavour to bend the limb to a rigidly designed splint. Calipers need to be carefully made to avoid pressure on insensitive skin and it is essential that patients and parents be taught to remove appliances and boots several times a day to inspect for signs of skin irritation. Boots with laces that extend to the toes are a valuable safety precaution, so that insensitive feet may be correctly situated under vision.

Below the knee, the use of inside and outside irons, T-straps, front and back stops all have the usual role to play in controlling various paralyses of the foot. A simple straight caliper is usually best for the unstable knee but as the child grows older it is advisable to fit a knee hinge to facilitate sitting at a school desk.

The importance of physiotherapy and occupational therapy cannot be over-emphasised. Centralisation of these services allows for group therapy that in itself provides an important boost for the patient. In this regard we are fortunate in having the facilities of the Hope School and Homes. Very good physical amenities exist, and staff enthusiasm and expertise are outstanding. The children progress steadily from the pool to parallel bars and ultimately to independent walking.

Total patient rehabilitation must not be neglected. Adequate schooling is essential and the provision of workshop and other facilities that can equip handicapped patients with a practical training will enable them to take their rightful place in society.

John Gallsworthy has observed "A niche of usefulness and a self-respect exists for every man however handicapped, but that niche must be found for him."

\section{SUMMARY}

The management of myelomeningocoele calls for an energetic and co-ordinated treatment regime that involves several disciplines. The orthopaedic surgeon must recognise and assess function. Insensitive skin precludes the use of manipulations, plaster casts and splints, and the treatment is surgical in the first instance. Division and elongation of tight structures will reverse otherwise progressive contrac- tures and joint dislocations, and selected muscle rebalancing by tendon transfers can prevent relapses. Joint arthrodesis may play a part but only in conjunction with rebalancing operations.

A subsequent unified programme of rehabilitation enables the majority of these patients to walk independently and many will lead useful lives.

\section{REFERENCES}

1. Brookes, M. and Wardle, E. M. (1962): Muscle action and the Shape of the Femur. Journal of Bone and Joint Surgery. 44B. 398.

2. Brown, A. (1968): A Simple Method of Fusion of the Subtalar Joint in Children. Journal of Bone and Joint Surgery. 50B. 364.

3. Grice, D. S. (1952): An Extra-Articular Arthrodesis of the Subastragular Joint for Correction of Paralytic Flat Feet in Children. Journal of Bone and Joint Surgery. 34A. 927.

4. Handelsman, J. E. (1968): Treatment of Congenital Vertical Talus. Journal of Bone and Joint Surgery. 50B. 439.

5. McKibben, B. and Porter, R. W. (1967): The incidence of Vitamin C Defficiency in Meningomyelocele. Develop. Med. Child Neurol. 9. 338.

6. Salter, R. B. (1961): Innominate Osteotomy in the Treatment of Congenital Dislocation and Subluxation of the Hip. Journal of Bone and Joint Surgery. 43B. 518.

7. Seymour, N. and Evans, D. K. (1968): A Modification of the Grice Sub-Talar Arthrodesis. Journal of Bone and Joint Surgery. 51 B. 372.

8. Sharrard, W. J. W. (1964): Posterior lliopsoas Transplantation in the Treatment of Paralytic Dislocation of the Hip. Journal of Bone and Joint Surgery. 46B. 426.

9. Sharrard, W. J. W. (1964): The Segmental Innervation of the Lower Limb Muscles in Man. Annals of the Royal College of Surgeons of England. 35 (2). 106.

10. Sharrard, W. J. W. (1968): Spinal Osteotomy for Congenital Kyphosis in Myelomeningocoele. Journal of Bone and Joint Surgery. 50B. 466.

11. Solomon, L. and Handelsman, J. E. (1967): The Treatment of Club Foot. South African Journal of Surgery. 5 (1). 31.

\title{
The Social Worker in the Spinal Defects Team
}

\author{
MRS. N. SHNEIER
}

Social Worker, Transvaal Memorial Hospital for Children, Johannesburg

\begin{abstract}
The social worker attached to the Spinal Defects Clinic is involved with the personal problems of the patients and their parents. Some of these problems existed before the child was born, and now become unbearable, but many others are the result of having a handicapped child in the family. Some families find the additional strain too great, and there is a threatened collapse of the marriage. Intensive casework and counselling with these parents must then be undertaken in an effort to sort out feelings and come to some solution for the future. One of the commonest causes of ill-feeling is guilt and the difficulty of apportioning blame.

The physical effects of myelomeningocoele extend right through the body. Besides the question of increase in head size, there may be weakness in the legs, the bowels and the bladder. Some children may have all of these difficulties; some perhaps, only one, and that in a very slight degree To the parents, on the whole, the one which is most disturbing emotionally is increase in the size of the head, though the one that causes most trouble practically is weakness of bowels or bladder. But certainly more important to
\end{abstract}

most people than any physical handicap is whether or not the child is normal in intelligence. As a rule, acceptance comes more easily if it is.

For most parents the first contact with the hospital is in the ward, as most children are admitted for investigation and treatment soon after birth. Many people know nothing at all of the condition, and to meet it for the first time in their own child is an intensely alarming situation, and one which is liable to evoke very strong feelings of guilt. Nor are they helped, in some cases, by local doctors and nurses who have no faith in the modern development of treatment for children; and those who have been told that the best they can hope for is an early death, may be faced with the painful return of hope for a child already mourned. After the first shock is over, most people are very anxious for as much information as they can get. Sympathetic and careful explanation by the medical and nursing staff at this stage does a great deal to make things less mysterious and less frightening.

Ideally, all the parents should be seen by the social 
worker on the first admission. Some will need much more help than others, but all are helped by support at this critical point. They need to tell someone that every care was taken during pregnancy and when the baby was born. They need to be given acceptance of their usually unexpressed resentment that this should happen to them in spite of it all. They need to be shown that they are not "facing the music" alone; that the hospital is not just turning out human guinea pigs, but is concerned with the functioning of the patients as individual children in a family and in the community.

A problem is always the result of the impact of an external situation on the person concerned, and it is not always the mother of the most handicapped baby who has the greatest difficulty in accepting it. Lauren is a pretty little girl of above average intelligence. Her legs and bladder are affected, but she has started to walk, wearing calipers. Her mother, an emotionally immature person, has never been able to accept the condition. It is only when she brings Lauren to the clinic that she allows her to wear a dress, otherwise she always has to wear jeans. This mother cannot bear the thought that other people will see that she has a handicapped child. She cannot stand the stares, and blames people for offering sympathy.

When they are discharged from hospital following their first admission for treatment, most of the babies will be going home for the first time. They have come from local hospitals or maternity homes, or perhaps, from home after only a few hours of life. Often there are special nursing routines for the mother to follow. These produce anxieties which are in addition to her normal anxieties about whether she can be a good mother. If there is a valve in the baby's head, she may be told to care for it in order to increase its efficiency. There may be some paralysis of the bladder which requires manual expression to empty it adequately. The mother will be taught all these procedures before the baby leaves the ward, but it will be a very different thing to carry them out on her own at home.

If there are no crises or setbacks, development is watched through the Spinal Defects Clinic. If the mental development is proceeding at a reasonable pace, probably the next big question is locomotion. If the child's legs are weak or deformed, he may need lengthy surgical treatment and then an arduous routine of calipers and physiotherapy before he can walk. While this complicated process is going on, the mother needs relief from the physical burden of carrying the growing child around for long distances. He also needs to be able to move around on his own where his interest takes him, without being totally dependant on his mother.

One of our fathers has solved this problem for his daughter by transferring the pedals to the handle-bars of her tricycle. She now has the freedom of the house and the garden. This release from dependecny has made an enormous difference to the morale of the child, and has freed her mother for her other household chores.

Discharge from hospital after intensive orthopaedic treatment, on a splint or in plaster, can bring its own complications in weight and position, which may involve removing pieces from prams or push-chairs. One picks the brains of the more ingenious fathers to help those less talented.

There are some children, and not always those with a very enlarged head, who are very severely mentally as well as physically handicapped. For their parents, it is inevitably a bitter thing that the treatment which has done so much for so many others whom they meet at the clinic cannot help them. This treatment has, perhaps only prolonged their years of heavy physical and emotional strain. The physical task of lifting a helpless four or five-year-old is greater than some people might imagine. Very often one finds that few relatives or friends will offer to relieve the parents or help in the child's care. Admittedly, one suspects that this is, at least in part, due to the early attitude of the parents who have no help; the overwhelming feeling of guilt and responsibility that makes them feel that it is their doing, and that they alone must take the consequences. This means they become slaves to the handicapped baby, and reject all their other relationships. This attitude is not generally understood by other people, so that later, when exhaustion, if nothing else, has persuaded the parents they need help, it is only rarely offered.

Especially when the child is a first child, one of the worst problems is the parents' agonised dread of having another handicapped child. They would like more children, and a brother or sister would bring much happiness and encouragement to the child they have, but fear holds them back. Yet, if things go fairly smoothly, by the time our patient is two or three, tension has relaxed, and very often another child is born. In our clinic, the whole staff and all the other parents watch the pregnancy with great concern. I have even had telephone calls from interested mothers asking whether the baby has been born, and, most important, is it normal. Some parents never manage to come to any solution of this problem and the patient remains an only child with all the additional handicaps associated with this state. The available genetic facts are given to those parents who want them, but they are not very encouraging, and it is fortunate that having another child depends on emotions and feelings and not just on sterile facts. Contraceptive information is also given when required.

Together with the condition of the legs, control over bowels and bladder is the other big physical factor. Some children seem to manage bowel control quite well. As for the bladder, some develop adequate control, or can achieve it with manual expression. For those whose bladders cannot be completely emptied like this, there is the danger of frequent infection, and so it may be necessary for the child to be given an ileal bladder. Although most mothers acknowledge the child is better in health for it, it is a very mutilating operation which may arouse fear and resentment in the child who has it, or the mother who has to cope with it. Fathers also, in our experience, find it difficult to come to terms with this operation.

This clinic serves a wide area, and parents have to bring their children many miles to see the doctors. It is our experience that children learn to walk more rapidly if they attend a treatment centre daily. As there is only one place providing comprehensive care and treatment, it is often necessary for the children to be admitted full-time. For many people it is a very hard decision to send their child away from home at such an early age. Most accept it though, because the alternative home tuition cannot provide as much in the way of schooling and does nothing to give the child that vital widening of its social contacts which an ordinary school gives to all normal children. Mothers usually raise this important question of schooling at an early age and they need to be told as much as possible about available facilities, and to work through their own ideas and feelings about it.

For many of these children permanent institutional care is advised as a long-term plan by the medical staff, with home-care and part-time placement in the early years. This seems to be the only reasonable solution, not only for the sake of the parents, but perhaps even more, for the sake of other normal children in the family, who may suffer very real deprivation if their parents are not helped with the care of the handicapped child.

There are problems in the future of which we, as yet, know nothing. Most of the children attending the clinic are very young. None whom I know are anywhere near employment age. After that, for some at least, there will come the question of marriage and genetic advice, and their associated very personal questions. Some of these children are doing very well as children, but how will they make out as adults in a very competitive society? All these questions lie in the future, and it will be many years before any sort of answer can be worked out. In the working out there will be a great deal of help and support needed from the social workers involved. 